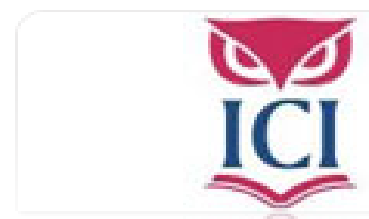

IUS. Revista del Instituto de Ciencias Jurídicas de Puebla A.C.

ISSN: $1870-2147$

revista.ius@hotmail.com

Instituto de Ciencias Jurídicas de Puebla A. C.

México

López Feldman, Aarón B.

Los caminos de la coerción

IUS. Revista del Instituto de Ciencias Jurídicas de Puebla A.C., núm. 19, 2007, pp. 196-199 Instituto de Ciencias Jurídicas de Puebla A. C.

Puebla, México 
EVENTOS

para este particular como código de familia, el sustrato teórico y el aparato conceptual que se utiliza, parte de la teoría y la normativa civil, adaptándolo a las particulares exigencias de la familia, no sólo desde el punto de vista jurídico, sino también desde el punto de vista político y social.

En cualquier caso, los cambios que se producen en los modelos familiares tradicionales, los problemas que trae aparejado el desarrollo científico-tecnológico en el ámbito ético, sus repercusiones en las normas jurídicas encargadas de regular las relaciones que se establecen, llaman a la reflexión y al debate para lograr aunar voluntades en la consecución del objetivo común que debe mover a la humanidad hacia una sociedad civilizada, de intercambio, tolerancia y aceptación.

Con el propósito de aportar a este proceso reflexivo acerca de la familia y las modificaciones que se producen en torno a ella, el Instituto de Ciencias de Puebla convoca a la jornada científica sobre Transexualidad, Homosexualidad y Problemas de Género en la Familia del siglo xxI, que reunirá a juristas y otros profesionales a fin de debatir acerca de temas tan significativos como las parejas del mismo sexo, la legitimidad o ilegitimidad de sus uniones, la transexualidad y sus consecuencias en el ámbito civil y familiar, la filiación a partir de la aplicación de las técnicas de reproducción huma- na asistida, la violencia doméstica, las familias monoparentales y las nuevas formas alternativas de solucionar los conflictos en esta sede, entre otras temáticas.

Hasta ahora se tiene confirmado que en el programa participarán profesionistas de diversas universidades del mundo como conferencistas principales, los que se reunirán durante dos días a discutir sobre los aspectos señalados y, sobre todo, la situación que presentan éstos en la actualidad social de México.

\section{Los caminos de la coerción}

Aarón B. López Feldman

\section{El autor de este ensayo aborda el pa- rentesco de la tortura y la prisión en el desarrollo de sus técnicas a través de los siglos}

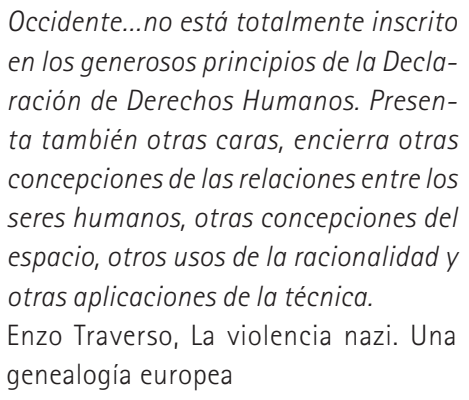
en los generosos principios de la Declaración de Derechos Humanos. Presenta también otras caras, encierra otras concepciones de las relaciones entre los seres humanos, otras concepciones del espacio, otros usos de la racionalidad y otras aplicaciones de la técnica. Enzo Traverso, La violencia nazi. Una genealogía europea

Es bien sabido, y vitoreado, que el siglo $\mathrm{xx}$ fue testigo de una amplia variedad de innovaciones tecnológicas que transformaron radical- 


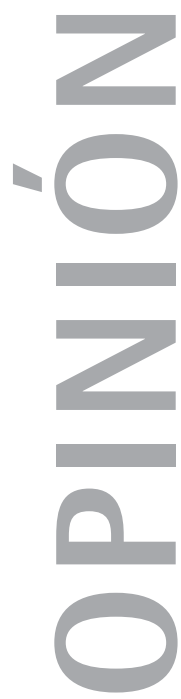

mente tanto el orden económico y social como el ejercicio de la vida cotidiana. Ha pasado casi desapercibido, sin embargo, que durante este siglo se desplegaron también una serie de innovaciones técnicas enfocadas en intervenir en los aspectos más intimos de la conducta y la subjetividad humana. Nuestro presente debe lo que es no sólo al desarrollo de las tecnologías centradas en la producción de bienes y servicios, sino también al despliegue de aquello que Michel Foucault llamara las "tecnologías de poder", enfocadas en el gobierno de la población y de los sujetos.

Dentro del amplio campo de acción de las tecnologías políticas, es posible destacar, por su vigencia, un área en particular: la reinvención de la tortura como medio de interrogación y su vinculación con las técnicas de la prisión. En la segunda mitad del siglo xx, la forma dominante de la tortura para obtener información dejó de estar basada en el cuerpo y la producción calculada del dolor, para enfocarse en el sujeto y las diversas formas de intervenir en su voluntad, su conducta y su resistencia. El giro de la tortura hacia el sujeto, ha sido visto como el resultado directo de más de cinco décadas de investigaciones psicológicas, impulsadas por la CIA en el marco de la Guerra Fría, enfocadas en especializar las técnicas de interrogación. Sin negar lo anterior, considero que la rein- vención de la tortura forma parte de un proceso más añejo caracterizado por el despliegue, desde el siglo XIX, de ciertas técnicas de coerción que actúan sobre los sujetos a través de un trabajo detallado sobre el tiempo y el espacio.

Con la abolición de la tortura judicial, forma milenaria de castigar y de obtener confesiones, y el establecimiento de la prisión moderna, las técnicas para producir dolor fueron sustituidas por técnicas para actuar sobre el sujeto; técnicas de coerción que se ejercen en un espacio propio, cerrado en sí mismo y alejado de la mirada pública. Más que el cuerpo doliente, el objeto de la acción carcelaria es el sujeto cognoscible y manipulable; se busca entonces que el ámbito de acción sobre el sujeto se dé a través del manejo de su espacio y de su tiempo. Con ello, el ejercicio de la coerción seguirá utilizando el cuerpo, sin duda alguna, pero buscando tener el menor contacto directo con él.

El espacio de la prisión no es únicamente el del encierro, ni su tiempo el de la simple monotonía. La prisión sitúa a cada sujeto en un lugar propio; asigna a cada instante del día un lugar y una acción; regula los lapsos y los ámbitos de sueño, de vigilia, de actividad, de reposo, de reunión y de aislamiento; estipula las formas, lugares y ritmos en que debe pasarse de una ocupación a otra. En el marco de la prisión, el tiempo y el espacio son utiliza- 
dos como técnicas de coerción que permiten no sólo privar de la libertad, sino también vigilar, conocer e intervenir en los sujetos. Y será precisamente el uso del tiempo y del espacio como técnicas de coerción lo que sustentará la reinvención de la tortura. He aquí pues la paradoja: las bases de lo que será la nueva forma de la tortura en la segunda mitad del siglo xx y principios del xxI emergen con la abolición de la tortura judicial y el triunfo de la prisión en los siglos XVIII y XIX.

Después de más de un siglo de su prohibición, la tortura como medio de interrogación volvió a ser retomada con toda su fuerza como práctica de Estado. Pero, poco a poco, sus procedimientos dejaron de ser los de antaño y comenzaron a girar en torno a la tecnología de la coerción que da vida a la prisión. Se desarrollaron así nuevas técnicas de tortura que buscan llegar al sujeto, manipular su voluntad y su conducta, pero teniendo el menor contacto físico con él y alejadas lo más posible de la producción directa de dolor. Una vez más, la razón para alejarse del cuerpo doliente no fue la benevolencia, sino más bien la incesante búsqueda de la eficacia. Los últimos dos milenos mostraron que la producción calculada de dolor era un medio ineficiente para producir información, por lo cual había llegado la hora de buscar nuevas formas que abrieran otros caminos posibles; los mecanismos de la prisión y los terrenos de la psicología se presentaron entonces como los ámbitos ideales para esta empresa. El tiempo y el espacio serán utilizados ahora para desorientar a los sujetos, nulificar su voluntad y su resistencia, y conducirlos a un estado en el que puedan proporcionar información fidedigna. Para ello, se creará en torno al sujeto una realidad completamente alejada de los patrones temporales, espaciales y sensoriales a los que estaba acostumbrado. Los límites de la nueva forma de la tortura se jugarán algunas veces en torno a la creación de un medio ambiente invariable, y en otras con base en la construcción permanente de lo discontinuo. Con la finalidad de privar al sujeto de todo estímulo sensorial, la luz, los sonidos y los olores serán eliminados o bien se mantendrán inmutables. A su vez, la alimentación, el sueño, las sesiones de interrogación y todas las actividades fundamentales serán llevadas a la irregularidad.

Las nuevas técnicas de la tortura ocuparon rápidamente un lugar central en las labores de inteligencia estadunidense, principalmente a partir de la guerra de Vietnam, y posteriormente se expandieron a lo largo del mundo, como parte del combate al comunismo y la "subversión”. Con el fin de la Guerra Fría, la aplicación de estas técnicas bajó un poco su intensidad, sin embargo volvieron a situarse en una posición 
privilegiada a inicios del siglo XXI. Ciertas zonas del teatro de operaciones de la presente guerra global se han convertido en espacios de interrogación en los cuales las nuevas técnicas de la tortura no sólo se han aplicado sistemáticamente, sino que incluso han sido potenciadas. Parte fundamental de esta potenciación está vinculada con el despliegue, en años recientes, de las prisiones de "súper-máxima seguridad", basadas en el aislamiento total y permanente de los internos, la eliminación de los canales de comunicación y del contacto físico, la monopolización de los estímulos sensoriales y la maximización del control y la vigilancia. Los elementos de esta nueva tecnología penitenciaria han sido rápidamente trasladados a las prácticas de la tortura del presente siglo, conduciendo incluso a la construcción, en Guantánamo, del primer centro de detención y extracción de información modelado plenamente en torno a sus lineamientos.

Constantemente se habla de los centros de detención e interrogación localizados en Afganistán, Guantánamo e Irak como simples prisiones militares cuya relación con las prisiones "regulares" es natural y evidente. Sin embargo, la naturaleza de esta relación se ha ido construyendo históricamente desde siglos atrás, y tras su aparente normalidad se desvela el despliegue de toda una tecnología de la coerción. No debemos ver en la reinvención de la tortura una simple extrapolación de los mecanismos de la prisión. Si bien ambos campos se basan en la codificación del tiempo y del espacio como el medio fundamental de la coerción, sus objetivos son diferentes; no buscan producir los mismos efectos. El espacio y el tiempo de la prisión deben actuar como técnicas de vigilancia, de control, de castigo y de reforma, mientras que el espacio y el tiempo de la tortura deben actuar como técnicas de manipulación, de ruptura, de supresión.

La reinvención de la tortura no es un epifenómeno de la prisión, ni es tampoco su resultado directo e inevitable; más bien ambos comparten una matriz común, una y otro forman parte del despliegue de los procedimientos de coerción que, haciendo del espacio y del tiempo sus medios de ejercicio, buscan llegar al sujeto. Hasta el momento, los procedimientos que conforman la prisión han dado sustento a una buena parte de la nueva forma que ha tomado la tortura. Falta ver si, en los tiempos que están por venir, algunas de las técnicas dirigidas a manipular la conducta, quebrantar la resistencia y suprimir la voluntad empiezan a abrir nuevas vías en torno al castigo, la vigilancia y la reforma del sujeto. Habrá que estar atentos pues, no sólo a la forma en que la tortura se expande ante nosotros, sino también a las nuevas rutas que pueda abrir en los caminos de la coerción. 